\title{
Clinical course of tracheobronchopathia osteochondroplastica
}

\author{
Hyun Kyu Cho, Byeong-Ho Jeong, Hojoong Kim
}

Division of Pulmonary and Critical Care Medicine, Department of Medicine, Samsung Medical Center, Sungkyunkwan University School of Medicine, Seoul, Republic of Korea

Contributions: (I) Conception and design: HK Cho, H Kim; (II) Administrative support: BH Jeong; (III) Provision of study materials or patients: HK Cho, H Kim; (IV) Collection and assembly of data: All authors; (V) Data analysis and interpretation: HK Cho, BH Jeong; (VI) Manuscript writing: All authors; (VII) Final approval of manuscript: All authors.

Correspondence to: Hojoong Kim, MD, PhD. Division of Pulmonary and Critical Care Medicine, Department of Medicine, Samsung Medical Center, Sungkyunkwan University School of Medicine, 81 Irwon-ro, Gangnam-gu, Seoul 06351, Republic of Korea. Email: hjk3425@skku.edu.

Background: Tracheobronchopathia osteochondroplastica (TPO) is characterized by the presence of diffuse cartilaginous or bony submucosal nodules that lead to airway lumen narrowing. So far, there was no study in South Korea analysing a large number of TPO patients. We aimed to elucidate its treatment strategy and clinical course by analysing the characteristics of TPO patients.

Methods: In this retrospective study, we reviewed the clinical data of 40 patients diagnosed with TPO by bronchoscopy between October 1997 and April 2019 at a single referral hospital.

Results: Of the 40 patients, 26 (65.0\%) were male and the median age was 63.0 years. The most common symptom was cough $(\mathrm{n}=12,30 \%)$. Pulmonary function test (PFT) revealed an obstructive pattern in 10 (25.7\%) patients. Chest computed tomography (CT) scan showed 23 (62.6\%) patients with diffuse narrowing and calcified nodules. In bronchoscopy, the entire trachea was found to be involved in $30(75.0 \%)$ patients and airway narrowing was identified in $6(15.0 \%)$ patients. Endobronchial biopsies were obtained from 15 patients and the most common findings included typical cartilaginous and bony tissues $(n=14,93.3 \%)$. Since most patients were asymptomatic or had mild symptoms, they did not undergo any specific treatment. Of the 19 symptomatic patients, 2 (5.0\%) patients received laser therapy for treating tracheal stenosis.

Conclusions: TPO is a slowly progressing disease and is well managed with conservative therapies. Although TPO shows a distinctive pattern by bronchoscopy, it follows a benign clinical course.

Keywords: Baseline characteristics; bronchoscopic interventions; bronchoscopy; clinical course; tracheobronchopathia osteochondroplastica (TPO)

Submitted May 11, 2020. Accepted for publication Sep 02, 2020.

doi: $10.21037 /$ jtd-20-1898

View this article at: http://dx.doi.org/10.21037/jtd-20-1898

\section{Introduction}

Tracheobronchopathia osteochondroplastica (TPO) is an idiopathic benign disease characterized by the presence of diffuse cartilaginous or bony submucosal nodules protruding into the tracheobronchial lumen. The posterior membranous wall is distinctively spared because the nodules mainly originate in airway cartilages (1). TPO is rarely identified by bronchoscopy or chest computed tomography (CT) with a reported incidence of approximately $0.3 \%$ (3/1,000 autopsies) (2,3). The English physician, Wilks, first observed TPO in autopsy specimens, which was diagnosed as tuberculosis in the 19th century (4).

TPO was mostly found incidentally at autopsy due to its benign and asymptomatic nature. However, it could be associated with specific symptoms, such as recurrent pneumonia, foreign-body sensation, and pleuritic chest pain (5). Since a better description of the disease and various diagnostic techniques are currently available, TPO is being more widely recognized (1).

Most large studies were conducted by Western countries, China, and Japan, leading to a better understanding of 
the clinical characteristics of TPO (5-7). Since most TPO patients were studied as case reports in South Korea, there was no data on large patient groups. Therefore, we aimed to analyse the clinical manifestation of TPO in 40 patients to identify its treatment strategy and clinical course. We present the following article in accordance with the STROBE reporting checklist (available at http://dx.doi. org/10.21037/jtd-20-1898).

\section{Methods}

\section{Study population}

In this retrospective study, we reviewed the clinical data of 40 patients who were diagnosed with TPO by bronchoscopy with or without histopathologic findings between October 1997 and April 2019 at a single referral hospital (Samsung Medical Center, Seoul, Republic of Korea). The inclusion criteria were the presence of typical endoscopic findings of TPO (6). The study was conducted in accordance with the Declaration of Helsinki (as revised in 2013). The institutional review board of the Samsung Medical Center approved this study (IRB No. 2020-03-035001). Patient consents were not needed because the study was retrospective in nature.

\section{Definition and data collection}

TPO is defined by the presence of white or yellow coloured multiple cartilaginous or bony nodules on the wall of the tracheobronchial lumen excluding membranous parts measuring 1 to $6 \mathrm{~mm}$ in diameter by bronchoscopy with or without histopathologic results $(1,8,9)$. We divided TPO into the following three stages according to the bronchoscopic visualization characteristics and histopathologic results: Stage I (early stage, mild grade), Stage II (middle stage, moderate grade), and Stage III (late stage, severe grade) (7). Histopathologic results of TPO showed the presence of either cartilage or bone in the submucosa of biopsy specimens (10-12).

Data were collected according to the demographic characteristics, pulmonary function tests (PFTs), radiologic findings, bronchoscopic findings, histopathologic results, treatment details, and clinical course by reviewing the medical records. Blood samples were drawn from patients for measuring calcium and phosphate levels when diagnostic bronchoscopy was performed. PFTs were performed before and after bronchoscopy and were classified as follows: obstructive pattern when the forced expiratory volume in 1 second/forced vital capacity $\left(\mathrm{FEV}_{1} / \mathrm{FVC}\right)$ was $70 \%$; restrictive pattern when $\mathrm{FVC}$ was $<80 \%$ with $\mathrm{FEV}_{1} / \mathrm{FVC}$ $\geq 70 \%$; combined pattern when FVC was $<80 \%$ with $\mathrm{FEV}_{1} /$ $\mathrm{FVC}<70 \%$; or normal when $\mathrm{FEV}_{1} / \mathrm{FVC} \geq 70 \%$ with FVC $\geq 80 \%(13,14)$. Chest X-ray data were analysed for tracheobronchial stenosis and calcification. Chest CT scans were evaluated for tracheal narrowing and the presence of submucosal nodules and calcification.

\section{Statistical analysis}

Continuous variables were expressed as medians with interquartile ranges (IQRs) and categorical data were presented as frequency (n) and percentages (\%). All data were analysed using the SPSS version 25.0 (IBM Corp., Armonk, NY, USA) software.

\section{Results}

\section{Baseline characteristics}

Baseline characteristics are represented in Table 1. Our study group included 26 men $(65.0 \%)$ and 14 women (35.0\%) with a median age of 63.0 (IQR: 55.3-70.8) years. Seventeen patients were active or former smokers (42.5\%). The most common symptom was cough $(\mathrm{n}=12,30.0 \%)$. Other clinical manifestations included dyspnoea on exertion $(\mathrm{n}=6,15.0 \%)$, increased sputum production $(\mathrm{n}=5,12.5 \%)$, and haemoptysis $(n=4,10.0 \%)$. However, more than half of the patients were asymptomatic $(\mathrm{n}=21,52.5 \%)$. Lung cancer was found in some patients $(\mathrm{n}=15,37.5 \%)$ and $7(17.5 \%)$ patients had a past history of pulmonary tuberculosis. More than half of the patients $(\mathrm{n}=23,57.5 \%)$ visited the hospital to evaluate lung nodules or masses suspicious for lung cancer and $14(35.0 \%)$ patients were referred to the hospital because of abnormal chest CT findings such as tracheal nodules or narrowing.

\section{PFT and laboratory data}

Main results of the PFT and laboratory data are summarized in Table 2. PFTs were performed in 39 (97.5\%) patients. The median FVC was 3.62 (IQR: 2.76-4.06) L and the $\mathrm{FEV}_{1}$ was 2.35 (IQR: 1.89-2.84) L. Among them, $10(25.7 \%)$ patients had obstructive ventilatory defects and 2 patients had restrictive ventilatory defects. Normal spirometry was observed in $25(64.1 \%)$ patients. The 
Table 1 Baseline characteristics of the 40 patients

\begin{tabular}{lc}
\hline Variables & No. (\%) or median (IQR) \\
\hline Sex (males) & $26(65.0)$ \\
Age (years) & $63.0(55.3-70.8)$ \\
Smoking & $23(57.5)$ \\
Never & $14(35.0)$ \\
Former & $3(7.5)$ \\
Current & \\
Symptom & $12(30.0)$ \\
Cough & $6(15.0)$ \\
Dyspnoea & $5(12.5)$ \\
Sputum & $4(10.0)$ \\
Haemoptysis & $21(52.5)$ \\
No symptoms & $2(5.0)$ \\
Associated lung disease & \\
Lung cancer & $15(37.5)$ \\
Previous history of pulmonary & $7(17.5)$ \\
tuberculosis & \\
Reason for bronchoscopy & \\
Euspicious for lung nodules or & \\
Ehest CT abnormality & \\
Calcified nodules & \\
\hline
\end{tabular}

$I Q R$, interquartile range; CT, computed tomography.

median serum calcium and phosphate levels were 0.51 (IQR: 0.49-0.53) $\mathrm{mmol} / \mathrm{L}$ and 0.20 (IQR: 0.16-0.22) $\mathrm{mmol} / \mathrm{L}$, respectively. The results of all patients were within the normal range.

\section{Thoracic imaging}

Findings from thoracic imaging are represented in Table 2. In TPO patients, chest X-ray data showed irregularity, scalloping, narrowing or calcification of the trachea and main bronchi (15). Chest X-ray was performed in all patients, of which 39 patients showed normal findings. Only $1(2.5 \%)$ patient showed narrowing of the mid to distal trachea and both main bronchi. The characteristics of chest CT scans showed tracheal narrowing and multiple 1-3 mm diameter submucosal nodules with or without calcification in the trachea and main bronchi (3). Chest CT scans were performed in 37 patients, of which 12 (32.4\%) patients showed normal findings. Except for the negative CT scans, most of the chest CT findings showed diffuse narrowing and calcified nodules $(\mathrm{n}=23,62.2 \%)$.

\section{Bronchoscopic and histopathologic results}

The main bronchoscopic and histopathologic results are summarized in Table 2. Bronchoscopy was performed in all patients. The entire trachea was involved in 30 (75.0\%) patients. In 2 patients, the involvement extended to the right main bronchus and 1 patient showed involvement of both main bronchi. Seven patients showed involvement only in a part of the trachea: upper trachea in 2 patients, mid trachea in 2 patients, and lower trachea in 3 patients. Segmental bronchi were less involved (left lower bronchi in 1 patient, right middle bronchi in 1 patient, and right lower bronchi in 1 patient). Six patients (15.0\%) showed tracheal narrowing. According to the Zhu et al. classification system, our study showed that Stage II $(\mathrm{n}=35,87.5 \%)$ was the most common group, followed by Stage III ( $\mathrm{n}=5,12.5 \%)(7)$. Histopathologic results were obtained from 14 patients. Most findings included typical cartilaginous and bony tissues $(\mathrm{n}=13,92.9 \%)$. Only one patient showed squamous metaplasia of the tracheal epithelium.

\section{Treatment and clinical course}

The treatment and clinical course are summarized in Table 3. Since most patients were either asymptomatic or showed mild symptoms, they had no specific treatment. Antibiotics were prescribed for $5(12.5 \%)$ patients and symptomatic treatments (antitussives, expectorants) were performed in $3(7.5 \%)$ patients. Among the 19 symptomatic patients, 2 (5.0\%) patients received laser therapy for the improvement of tracheal stenosis. One of them visited the hospital for dyspnoea and haemoptysis, for which thoracic imaging and bronchoscopy were performed. After diagnosis of typical bronchoscopy findings and pathologically proven TPO, laser therapy was performed for treatment (Figure 1). After laser treatment, the patient had no worsening of dyspnoea and achieved symptomatic control with increased sputum during follow-up. The median follow-up duration of all TPO patients was 13.5 (IQR: 5.5-56.1) months 
Table 2 Laboratory findings, pulmonary function, radiologic, and histopathologic tests

\begin{tabular}{|c|c|}
\hline Variables & No. (\%) or median (IQR) \\
\hline \multicolumn{2}{|l|}{ Laboratory tests $(n=38)$} \\
\hline Calcium levels (mmol/L) & $0.51(0.49-0.53)$ \\
\hline Phosphate levels (mmol/L) & $0.20(0.16-0.22)$ \\
\hline \multicolumn{2}{|l|}{ PFTs $(n=39)$} \\
\hline FVC (L) & $3.62(2.76-4.06)$ \\
\hline $\mathrm{FEV}_{1}(\mathrm{~L})$ & $2.35(1.89-2.84)$ \\
\hline $\mathrm{FEV}_{1} / \mathrm{FVC}(\%)$ & 73 [69-78] \\
\hline Obstructive pattern & $10(25.7)$ \\
\hline Restrictive pattern & $2(5.1)$ \\
\hline Mixed pattern & $2(5.1)$ \\
\hline Normal & $25(64.1)$ \\
\hline \multicolumn{2}{|l|}{ Chest X-ray $(n=40)$} \\
\hline Both main bronchi narrowing & $1(2.5)$ \\
\hline Normal & $39(97.5)$ \\
\hline \multicolumn{2}{|l|}{ Chest CT $(n=37)$} \\
\hline Diffuse narrowing and calcified nodules & $23(62.2)$ \\
\hline Tracheal papillomatosis & $2(5.4)$ \\
\hline Normal & $12(32.4)$ \\
\hline \multicolumn{2}{|l|}{ Involved sites on bronchoscopy $(n=40)$} \\
\hline Entire trachea & $30(75.0)$ \\
\hline Extending to right main bronchus & $2(5.0)$ \\
\hline Extending to both main bronchi & $1(2.5)$ \\
\hline Partially involved only on the trachea & 7 \\
\hline Upper trachea & $2(5.0)$ \\
\hline Mid trachea & $2(5.0)$ \\
\hline Lower trachea & $3(7.5)$ \\
\hline Partially involved only on the bronchus & 3 \\
\hline Left lower bronchi & $1(2.5)$ \\
\hline Right middle bronchi & $1(2.5)$ \\
\hline Right lower bronchi & $1(2.5)$ \\
\hline \multicolumn{2}{|l|}{ Bronchoscopic stage $^{\dagger}$} \\
\hline Stage I & 0 \\
\hline Stage II & $35(87.5)$ \\
\hline Stage III & $5(12.5)$ \\
\hline
\end{tabular}

Table 2 (continued)
Table 2 (continued)

\begin{tabular}{lc}
\hline Variables & No. (\%) or median (IQR) \\
\hline Histopathologic findings $(\mathrm{n}=14)$ & $13(92.9)$ \\
Cartilaginous and bony tissues & $1(7.1)$ \\
Squamous metaplasia & \\
\hline${ }^{\dagger}$, TPO was divided into three stages according to the \\
characteristics of bronchoscopic visualization and histopathologic \\
results. IQR, interquartile range; PFT, pulmonary function test; \\
$\begin{array}{l}\text { FVC, forced vital capacity; FEV1, forced expiratory volume in } 1 \\
\text { second; CT, computed tomography; TPO, tracheobronchopathia } \\
\text { osteochondroplastica. }\end{array}$
\end{tabular}

Table 3 Treatment details and clinical course

\begin{tabular}{lc}
\hline Variables & No. (\%) or median (IQR) \\
\hline Treatment & $5(12.5)$ \\
Antitussives, expectorants, antibiotics & $3(7.5)$ \\
Antitussives, expectorants only & $1(2.5)$ \\
Haemostatics & $2(5.0)$ \\
Laser & $13.5(5.5-56.1)$ \\
Follow-up period for all patients (months) & \\
Aggravation of symptoms & $2(5.0)$ \\
Sputum & $1(2.5)$ \\
Dyspnoea & $1(2.5)$ \\
Chest discomfort & $15(37.5)$ \\
Follow-up for more than 36 months & $2(5.0)$ \\
Sputum & $1(2.5)$ \\
Chest discomfort & $1(2.5)$ \\
Mortality & $7(17.5)$ \\
Unknown & $1(2.5)$ \\
Brain metastasis & \\
\hline Pneumothorax & \\
\hline
\end{tabular}

$I Q R$, interquartile range.

and only 4 patients had aggravation of symptoms, which included sputum production in 2 patients, dyspnoea in 1 patient, and chest discomfort in 1 patient. Of the 15 (37.5\%) patients who followed up for more than 3 years, only 3 (20\%) patients showed a worsening of symptoms. Using symptomatic agents, all of them achieved remission of symptoms. After the diagnosis of TPO, 9 patients died, 


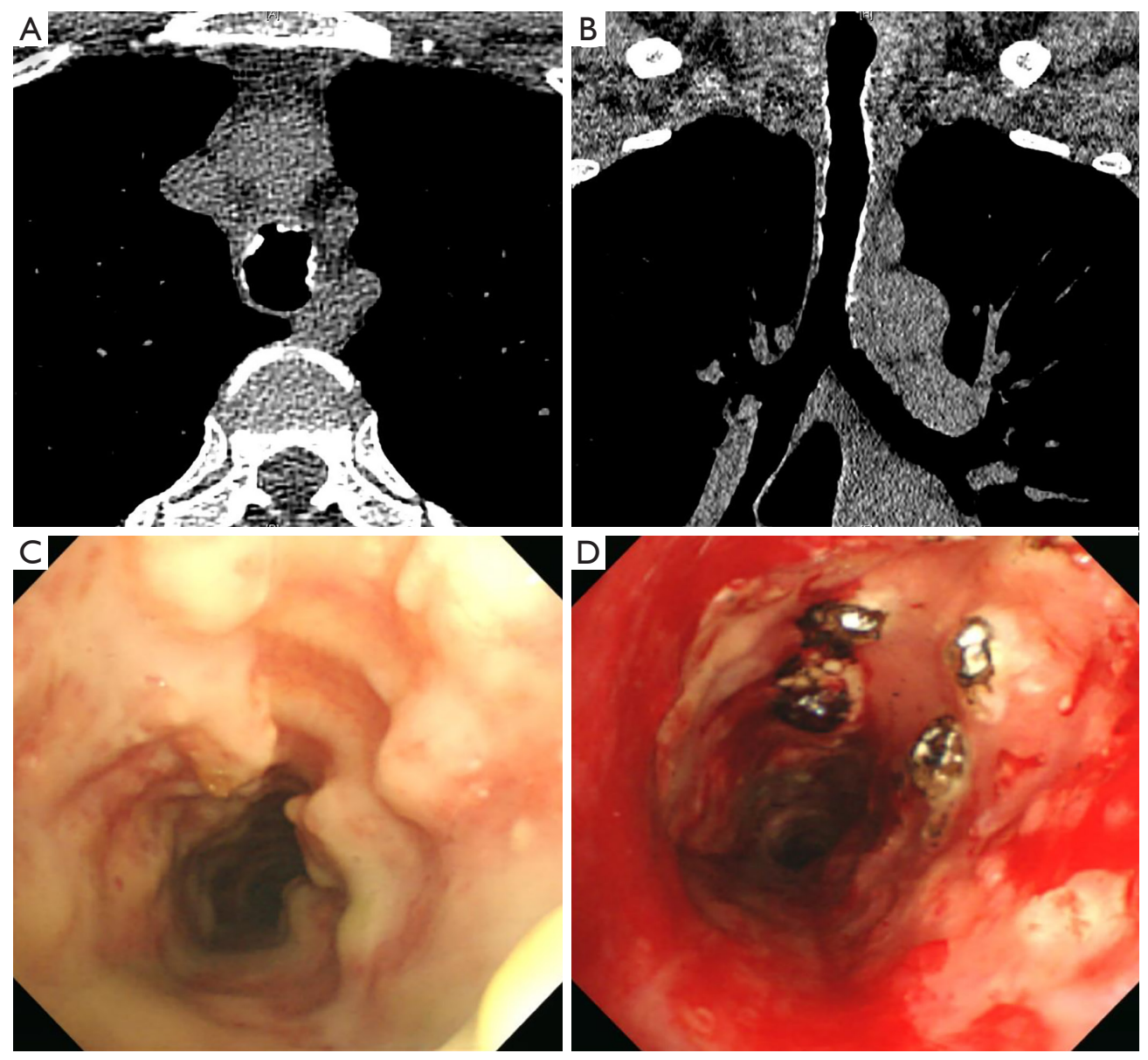

Figure 1 Laser therapy for tracheal stenosis due to TPO. The patient was a 52 -year-old woman. The main symptoms were dyspnoea and haemoptysis. Bronchoscopy and biopsy were conducted. The whole trachea was covered by cobblestone-like lesions and the biopsy specimen was histopathologically diagnosed as TPO. To relieve dyspnoea, Nd-YAG laser therapy was performed. After treatment, the symptoms improved and there were no complications. (A) Non-contrast axial chest CT scan shows calcified anterolateral nodules; (B) coronal reconstructed chest CT scan shows diffuse nodular calcification and the extent of involvement of TPO; (C) bronchoscopy reveals cobblestone-like nodules projecting into the lumen leading to airway narrowing; (D) after Nd-YAG laser therapy, some endobronchial nodules were cauterized and removed. TPO, tracheobronchopathia osteochondroplastica; Nd-YAG, neodymium-doped yttrium aluminium garnet; CT, computed tomography.

but the aetiology of death was unknown in 7 patients. The other 2 patients died of brain metastasis and pneumothorax.

\section{Discussion}

In our study, 40 patients with TPO showed typical bronchoscopic features. TPO patients showed various symptoms from asymptomatic to bronchial stenosis. The important point of this study was that it shows a specific finding in bronchoscopy, but it follows a benign course. Since the first case of TPO was described in 1857, more than 500 cases of TPO had been reported worldwide by April 2017 (7,16). The high incidence of TPO can be attributed to its asymptomatic or non-specific symptomatic nature. However, it is not well known in South Korea because no original article has been reported on TPO. Therefore, we summarized original articles including more than 10 patients written in English for comparison with previous reports in Table $4(6,7,17,18)$. In our study, the median age for diagnosis of TPO was 63.0 years, which was similar to the results from other studies $(19,20)$. According to a systematic review that analysed a total of 151 patients, 
Table 4 Systematic review of four original articles on TPO

\begin{tabular}{|c|c|c|c|c|}
\hline References & Nienhuis et al. [1990] (17) & Leske et al. [2001] (6) & Zhu et al. [2014] (7) & Luo et al. [2019] (18) \\
\hline Symptoms & $\begin{array}{l}\text { Cough }(66 \%) \text {, haemoptysis } \\
(60 \%) \text {, dyspnoea }(53 \%)\end{array}$ & $\begin{array}{l}\text { Chronic cough }(54 \%) \text {, } \\
\text { haemoptysis }(20 \%)\end{array}$ & $\begin{array}{l}\text { Chronic cough }(64 \%) \text {, } \\
\text { haemoptysis }(45 \%)\end{array}$ & $\begin{array}{l}\text { Cough }(47 \%) \text {, } \\
\text { haemoptysis }(23 \%) \text {, } \\
\text { expectoration }(21 \%)\end{array}$ \\
\hline PFT & $\begin{array}{l}\text { Normal }(14 \%) \text {, obstructive } \\
\text { defects }(71 \%)\end{array}$ & $\begin{array}{l}\text { Normal }(43 \%) \text {, obstructive defects } \\
(39 \%) \text {, restrictive defects }(18 \%)\end{array}$ & $\mathrm{N} / \mathrm{A}$ & $\mathrm{N} / \mathrm{A}$ \\
\hline Chest CT scan & $\begin{array}{l}\text { Intraluminal calcification } \\
(33 \%) \text {, normal }(42 \%)\end{array}$ & $\begin{array}{l}\text { Submucosal nodules }(74 \%) \text {, } \\
\text { submucosal calcification }(61 \%) \text {, } \\
\text { tracheal stenosis }(10 \%)\end{array}$ & $\begin{array}{l}\text { Beaded or scalloped } \\
(77 \%) \text {, calcification }(64 \%) \text {, } \\
\text { tracheal stenosis }(27 \%)\end{array}$ & $\begin{array}{l}\text { Submucosal calcification } \\
(87.5 \%), \text { normal }(12.5)\end{array}$ \\
\hline Histology & $\begin{array}{l}\text { Normal }(91 \%) \text {, squamous } \\
\text { metaplasia }(9 \%)\end{array}$ & $\begin{array}{l}\text { Squamous metaplasia ( } 48 \%) \text {, } \\
\text { cartilage }(38 \%) \text {, bone }(58 \%)\end{array}$ & $\begin{array}{l}\text { Cartilaginous }(61 \%) \text {, } \\
\text { bony }(78 \%), \text { squamous } \\
\text { metaplasia }(78 \%)\end{array}$ & $\begin{array}{l}\text { Squamous metaplasia } \\
(7 \%) \text {, ossification }(54 \%) \text {, } \\
\text { cartilage }(14 \%)\end{array}$ \\
\hline Treatment & $\begin{array}{l}\text { Cryotherapy }(6.7 \%) \text {, laser } \\
\text { therapy }(6.7 \%)\end{array}$ & $\begin{array}{l}\text { Inhaled corticosteroids (20\%), } \\
\text { antibiotics (17\%), laser therapy } \\
(2.4 \%)\end{array}$ & $\begin{array}{l}\text { Inhaled corticosteroids } \\
(36 \%)\end{array}$ & $\begin{array}{l}\text { Bronchoscopic treatment } \\
(4 \%)\end{array}$ \\
\hline Clinical outcome & Death $(0 \%)$ & $\begin{array}{l}\text { Asymptomatic }(24 \%) \text {, chronic or } \\
\text { recurrent symptoms }(76 \%) \text {, death } \\
(2.4 \%)\end{array}$ & $\begin{array}{l}\text { Remission of symptoms } \\
(86 \%) \text {, death }(4.5 \%)\end{array}$ & Death $(6.8 \%)$ \\
\hline
\end{tabular}

TPO, tracheobronchopathia osteochondroplastica; PFT, pulmonary function test; CT, computed tomography.

the mean age of TPO patients was 55.8 years $(6,7,17,18)$. Compared to our results (male, $65 \%$ ), two previous studies reported a higher prevalence of female TPO patients [73\% (21) and 66\% (19) respectively]. However, the abovementioned studies revealed that the female predominance was a result of the inclusion criteria. In systematic review $(6,7,17,18), 80 / 151(53.0 \%)$ patients had cough and 44/151 (29.1\%) patients had haemoptysis. Our study showed that chronic cough was the most common symptom, with a lower proportion of patients with haemoptysis. In another study, $88 \%$ of the patients had 1 or more symptoms but our results showed a higher prevalence of asymptomatic patients $(21 / 40,52.5 \%)(6)$. We observed that a patient could have many symptoms. More than half of the patients visited our hospital for suspected pulmonary nodules or masses, which were detected using thoracic imaging in another hospital, and the TPO was incidentally found during bronchoscopy.
Although TPO is a benign disease with a good prognosis, our study subjects showed a slightly higher incidence of lung cancer 15/40 (37.5\%). One possible explanation for this is that TPO was diagnosed concomitantly when diagnostic bronchoscopy was performed for suspected lung cancer. Leske et al. (6) showed that TPO was not related to an increasing incidence of malignant disease, and any such association is a coincidence.

In the current study, 10/39 (25.7\%) patients showed obstructive pulmonary function and 25/39 (64.1\%) patients showed normal ventilatory function. Two other studies reported an obstructive ventilatory defect in $7 / 8(87.5 \%)$ patients and $11 / 28(39.3 \%)$ patients $(6,20)$. These results suggest that our study patients were either asymptomatic or showed mild respiratory symptoms. In previous studies, serum calcium and phosphorus metabolic disorders have been linked to the aetiology of TPO $(1,7)$, although in our 
study, all patients had normal serum calcium and phosphate levels. In line with this, previous studies have also shown unchanged calcium and phosphate levels in TPO patients $(22,23)$. Chest radiography was performed in all patients $(\mathrm{n}=40)$, of which only $1(2.5 \%)$ patient was positive with narrowing of both main bronchi. Among our systematic review patients undergoing chest $\mathrm{X}$-rays, 59/71 (83.0\%) had negative results $(6,7,17)$. This suggests that it is difficult to obtain the typical chest X-ray appearance of TPO. Compared to chest X-ray findings, chest CT scans were more reliable for the identification of TPO. In our study, chest CT scans were available for most patients $37 / 40$ $(92.5 \%)$ and typical features were presented with calcified nodules and diffuse narrowing $(62.2 \%)$. These results were similar to previous studies in which the prevalence of CT scan results were $81.8 \%$ (7) and $74 \%$ (6). Chest CT scan was found to be more useful than chest roentgenography for the evaluation of TPO by thoracic imaging. Bronchoscopy is the only procedure that definitely confirms the diagnosis of TPO (1). In systematic review $(6,7,17,18)$, a total of 151 patients underwent bronchoscopy and typical bronchoscopic findings were observed in all of them. The characteristic findings were described as a stalactite cave, rock-garden, or cobble-stoned appearance $(24,25)$. It is reported that biopsies of airway luminal nodules were not usually necessary for the diagnosis of TPO because the bronchoscopic appearance itself was typical (26). Indeed, obtaining biopsies of TPO lesions are usually difficult because of the hardness of the lesions (24). However, submucosal biopsies are considered to discriminate against other airway disorders and malignancies such as amyloidosis, endobronchial sarcoidosis, tuberculoid calcinosis, relapsing polychondritis, tracheobronchial papillomatosis, granulomatosis with polyangiitis, and chondrosarcoma (27-30). We performed bronchoscopy in 40 patients and all of them had characteristic bronchoscopic findings. Therefore, bronchoscopy is the gold standard for the diagnosis of TPO $(31,32)$.

There is no definitive medical treatment for TPO. Since it is impossible to remove all the nodules, the treatment of TPO depends on disease symptoms, infection status, and the severity of the airway obstruction. In patients with cough, sputum, fever, and respiratory infections, the medical treatments to control infections and to relieve symptoms include antibiotics, antitussives, and hemostatics. For severe airway obstruction or recurrent obstructive infection, treatment modalities involve laser ablation, surgical resection, and radiotherapy (16). In systematic review $(6,7,17,18)$, tracheal stenosis or airway obstruction was present in 24 patients and 6 patients received cryotherapy, laser therapy, and bronchoscopic treatment. In patients who developed tracheal stenosis, neodymiumdoped yttrium aluminium garnet (Nd-YAG) laser therapy was considered $(33,34)$. We performed laser therapy in 2 (5\%) patients for tracheal stenosis. The 2 patients were followed up for 51.3 and 258.0 months. There was no disease progression to the extent that other bronchoscopic interventions were required during the follow-up period. While we followed up all patients, only $4(10 \%)$ patients showed aggravation of symptoms such as sputum production, chest discomfort, and dyspnoea but symptoms were relieved in all of them after the symptomatic treatment. Another study also showed good prognosis in which $86.3 \%$ of patients had a remission of symptoms to some extent (7). There is little information about the prevention or progression of TPO (35). In our study, the 15 patients who were followed up for more than 3 years showed no progression that required clinical interventions. Although 3 (20\%) patients showed worsened symptoms, they improved with conservative treatments. Since most TPO patients show slow progression, conservative care is usually sufficient $(28,36)$.

This study has several limitations. First, patients were initially selected by the typical TPO findings of bronchoscopy, therefore, patients who were diagnosed with TPO using chest CT findings were not selected. Second, our study did not reveal the aetiology of TPO. Although several hypotheses of TPO aetiology have been proposed, such as bone morphogenetic protein-2 (BMP-2) and transforming growth factor beta-1 (TGF- $\beta 1$ ) signaling, our results could not explain the pathophysiology. Several factors also have been proposed for its pathogenesis such as chronic infection, chemical or mechanical irritation, genetic factors, ozena, metabolic abnormalities, and malignancies (1,29,37-39). Further studies are needed to understand its aetiology (40). Finally, the cause of mortality was not extensively evaluated during the follow-up period. Therefore, we could not elucidate the association between TPO and mortality.

TPO is a rare disease of unknown aetiology characterized by the narrowing of the tracheobronchial tree causing the presence of diffuse cartilaginous or bony submucosal nodules. Since there was no large study including TPO patients in South Korea, not much was known about it. In this retrospective study, we tried to elucidate the baseline characteristics, treatment strategy, and clinical course of 
TPO. The disease is associated with a benign nature, and many patients have a variety of symptoms ranging from mild to severe. Although some patients with severe symptoms require bronchoscopic intervention, most patients require no specific treatment initially. During the long-term followup of TPO patients, disease progression was slow and conservative treatment was sufficient. Although TPO has a distinctive appearance in bronchoscopy, it follows a benign clinical course.

\section{Acknowledgments}

Funding: None.

\section{Footnote}

Reporting Checklist: The authors have completed the STROBE reporting checklist. Available at http://dx.doi. org/10.21037/jtd-20-1898

Data Sharing Statement: Available at http://dx.doi. org/10.21037/jtd-20-1898

Conflicts of Interest: All authors have completed the ICMJE uniform disclosure form (available at http://dx.doi. org/10.21037/jtd-20-1898). The authors have no conflicts of interest to declare.

Ethical Statement: The authors are accountable for all aspects of the work in ensuring that questions related to the accuracy or integrity of any part of the work are appropriately investigated and resolved. The study was conducted in accordance with the Declaration of Helsinki (as revised in 2013). The institutional review board of the Samsung Medical Center approved this study (IRB No. 2020-03-035-001). Patient consents were not needed because the study was retrospective in nature.

Open Access Statement: This is an Open Access article distributed in accordance with the Creative Commons Attribution-NonCommercial-NoDerivs 4.0 International License (CC BY-NC-ND 4.0), which permits the noncommercial replication and distribution of the article with the strict proviso that no changes or edits are made and the original work is properly cited (including links to both the formal publication through the relevant DOI and the license). See: https://creativecommons.org/licenses/by-nc-nd/4.0/.

\section{References}

1. Prakash UB. Tracheobronchopathia osteochondroplastica. Semin Respir Crit Care Med 2002;23:167-75.

2. Meyer CN, Dossing M, Broholm H.

Tracheobronchopathia osteochondroplastica. Respir Med 1997;91:499-502.

3. White BD, Kong A, Khoo E, et al. Computed tomography diagnosis of tracheobronchopathia osteochondroplastica. Australas Radiol 2005;49:319-21.

4. Sakula A. Tracheobronchopathia osteoplastica: its relationship to primary tracheobronchial amyloidosis. Thorax 1968;23:105-10.

5. Shigematsu Y, Sugio K, Yasuda M, et al. Tracheobronchopathia osteochondroplastica occurring in a subsegmental bronchus and causing obstructive pneumonia. Ann Thorac Surg 2005;80:1936-8.

6. Leske V, Lazor R, Coetmeur D, et al. Tracheobronchopathia osteochondroplastica: a study of 41 patients. Medicine (Baltimore) 2001;80:378-90.

7. Zhu Y, Wu N, Huang HD, et al. A clinical study of tracheobronchopathia osteochondroplastica: findings from a large Chinese cohort. PLoS One 2014;9:e102068.

8. Carr DT, Olsen AM. Tracheopathia osteoplastica. J Am Med Assoc 1954;155:1563-5.

9. Barthwal MS, Chatterji RS, Mehta A. Tracheobronchopathia osteochondroplastica. Indian J Chest Dis Allied Sci 2004;46:43-6.

10. Pounder DJ, Pieterse AS. Tracheopathia osteoplastica: a study of the minimal lesion. J Pathol 1982;138:235-9.

11. Katzenstein AA, Askin FB. Surgical pathology of nonneoplastic lung disease. Major Probl Pathol 1982;13:1-430.

12. Akyol MU, Martin AA, Dhurandhar N, et al. Tracheobronchopathia osteochondroplastica: a case report and a review of the literature. Ear Nose Throat J 1993;72:347-50.

13. Miller MR, Hankinson J, Brusasco V, et al. Standardisation of spirometry. Eur Respir J 2005;26:319-38.

14. Pellegrino R, Viegi G, Brusasco V, et al. Interpretative strategies for lung function tests. Eur Respir J 2005;26:948-68.

15. Zack JR, Rozenshtein A. Tracheobronchopathia osteochondroplastica: report of three cases. J Comput Assist Tomogr 2002;26:33-6.

16. Wang N, Long F, Jiang S. Tracheobronchopathia osteochondroplastica: two cases reports and review of literature. Medicine (Baltimore) 2016;95:e3396.

17. Nienhuis DM, Prakash UB, Edell ES. 
Tracheobronchopathia osteochondroplastica. Ann Otol Rhinol Laryngol 1990;99:689-94.

18. Luo T, Zhou H, Meng J. Clinical characteristics of tracheobronchopathia osteochondroplastica. Respir Care 2019;64:196-200.

19. Vilkman S, Keistinen T. Tracheobronchopathia osteochondroplastica. Report of a young man with severe disease and retrospective review of 18 cases. Respiration 1995;62:151-4.

20. Lundgren R, Stjernberg NL. Tracheobronchopathia osteochondroplastica. A clinical bronchoscopic and spirometric study. Chest 1981;80:706-9.

21. Härmä RA, Suurkari S. Tracheopathia chondroosteoplastica. A clinical study of thirty cases. Acta Otolaryngol 1977;84:118-23.

22. Swamy TL, Hasan A. Tracheopathia osteoplastica presenting with haemoptysis in a young male. Indian J Chest Dis Allied Sci 2010;52:119-21.

23. Coëtmeur D, Bovyn G, Leroux P, et al. Tracheobronchopathia osteochondroplastica presenting at the time of a difficult intubation. Respir Med 1997;91:496-8.

24. Prakash UB, McCullough AE, Edell ES, et al. Tracheopathia osteoplastica: familial occurrence. Mayo Clin Proc 1989;64:1091-6.

25. Doshi H, Thankachen R, Philip MA, et al. Tracheobronchopathia osteochondroplastica presenting as an isolated nodule in the right upper lobe bronchus with upper lobe collapse. J Thorac Cardiovasc Surg 2005;130:901-2.

26. Kirbaş G, Dağli CE, Tanrikulu AC, et al. Unusual combination of tracheobronchopathia osteochondroplastica and AA amyloidosis. Yonsei Med J 2009;50:721-4.

27. Chrysikos S, Karampitsakos T, Tzouvelekis A, et al. Coexistence of tracheobronchopathia osteochondroplastica and sarcoidosis: accidental finding or something more? J Bronchology Interv Pulmonol 2019;26:e7-8.

28. Ulasli SS, Kupeli E. Tracheobronchopathia osteochondroplastica: a review of the literature. Clin Respir J 2015;9:386-91.

Cite this article as: Cho HK, Jeong BH, Kim H. Clinical course of tracheobronchopathia osteochondroplastica. J Thorac Dis 2020;12(10):5571-5579. doi: 10.21037/jtd-20-1898
29. Chroneou A, Zias N, Gonzalez AV, et al. Tracheobronchopathia osteochondroplastica. An underrecognized entity? Monaldi Arch Chest Dis 2008;69:65-9.

30. Zaibi H, Fessi R, Dhahri B, et al. Tracheobronchopathia osteochondroplastica: end stage of tracheo-bronchial amyloidosis? Tanaffos 2019;18:272-5.

31. Li YY, Hu CP, Yang HZ, et al. The diagnostic value of flexible bronchoscopy in tracheobronchopathia osteochondroplastica. Zhonghua Jie He He Hu Xi Za Zhi 2009;32:489-92.

32. Abu-Hijleh M, Lee D, Braman SS. Tracheobronchopathia osteochondroplastica: a rare large airway disorder. Lung 2008;186:353-9.

33. Wong JS, Ng CS, Yim AP. Hemoptysis with multiple tracheal nodules. Chest 2005;128:3671-3.

34. Jabbardarjani HR, Radpey B, Kharabian S, et al. Tracheobronchopathia osteochondroplastica: presentation of ten cases and review of the literature. Lung 2008;186:293-7.

35. Williams SM, Jones ET. General case of the day. Tracheobronchopathia osteochondroplastica. Radiographics 1997;17:797-9.

36. Hussain K, Gilbert S. Tracheopathia osteochondroplastica. Clin Med Res 2003;1:239-42.

37. Baugnee PE, Delaunois LM. Mycobacterium aviumintracellulare associated with tracheobronchopathia osteochondroplastica. Eur Respir J 1995;8:180-2.

38. Shih JY, Hsueh PR, Chang YL, et al. Tracheal botryomycosis in a patient with tracheopathia osteochondroplastica. Thorax 1998;53:73-5.

39. Karlikaya C, Yuksel M, Kilicli S, et al. Tracheobronchopathia osteochondroplastica. Respirology 2000;5:377-80.

40. Tajima K, Yamakawa M, Katagiri T, et al. Immunohistochemical detection of bone morphogenetic protein-2 and transforming growth factor beta-1 in tracheopathia osteochondroplastica. Virchows Arch 1997;431:359-63. 